\title{
EFEITO INIBITÓRIO DE EXTRATOS VEGETAIS SOBRE Colletotrichum gloeosporioides - AGENTE CAUSAL DA PODRIDÃO DE FRUTOS DE MAMOEIRO
}

\author{
Luiz Fernando Ribeiro",2; Ivan Paulo Bedendo ${ }^{1 *}$ \\ ${ }^{1}$ Depto. de Entomologia, Fitopatologia e Zoologia Agrícola - ESALQ/USP, C.P. 9 - CEP: 13418-900 - Piracicaba, SP. \\ ${ }^{2}$ Bolsista do CNPq. \\ *e-mail: ipbedend@carpa.ciagri.usp.br
}

RESUMO: Extratos aquosos foram obtidos a partir de bulbilhos de alho, folhas de hortelã e mamona e frutos de pimenta. Após a incorporação destes extratos em BDA, obtendo-se concentrações de 100, $200,500,1000,5000$ e 10000 ppm, foi avaliado o crescimento e a produção de conídios de um isolado de Colletotrichum gloeosporioides, agente de podridão em frutos de mamoeiro. Os resultados demonstraram o efeito inibitório dos diferentes extratos a partir da concentração de 200 ppm. 0 extrato de alho inibiu o crescimento micelial, em porcentagens variáveis de 5,3 a $67,6 \%$, porém não atuou de modo expressivo sobre a produção de conídios. Em contraposição, os extratos de hortelã, mamona e pimenta promoveram inibição menos acentuada do crescimento de micélio, porém reduziram drasticamente a produção de conídios em níveis variáveis de 41 a $84 \%$, de acordo com as concentrações crescentes dos mesmos. As propriedades fungitóxicas detectadas nos extratos utilizados no ensaio evidenciaram o uso potencial dos mesmos como alternativa aos métodos físicos e químicos convencionalmente usados para o controle da doença.

Palavras-chave: Colletotrichum gloeosporioides, extrato vegetal, pós-colheita

\section{INHIBITORY EFFECT OF PLANT EXTRACTS ON Colletotrichum Gloeosporioides - THE CAUSAL AGENT OF POSTHARVEST ROT IN PAPAYA FRUITS}

\begin{abstract}
To evaluate the effect of plant extracts on the growth and the sporulation of Colletotrichum gloeosporioides, aqueous extracts from garlic, pippermint, castor bean and pepper were obtained and incorporated into potato-dextrose-agar (PDA) at concentrations of 100, 200,500, 1000, 5000 and 10000 $\mathrm{mg} / \mathrm{g}$. Micelial growth and the conidium production were evaluated in these media. All extracts exhibited inhibitory effect at the concentration of $200 \mathrm{mg} / \mathrm{g}$ and above. Garlic extracts inhibited micelial growth in the range of 5.3 to $67.6 \%$, it had, however no effect on sporulation. Peppermint, castor bean and pepper extracts promoted micelium inhibition and reduced the conidium production in the range of 41 to $84 \%$, according to the extract concentrations. It was demonstrated that the different extracts have antifungal activities and that they have a potential use as an alternative control in relation to physical or chemical methods.
\end{abstract}

Key words: Colletotrichum gloeosporioides, vegetal extract, postharvest

\section{INTRODUÇÃO}

As doenças de plantas são responsáveis por consideráveis perdas para as culturas de importância econômica, encontrandose, entre elas, as doenças de pós-colheita em frutíferas. Para reduzir os prejuízos, métodos físicos, químicos e biológicos vêm sendo empregados, visando o controle deste grupo de doenças (Eckert \& Ogawa, 1985; Wilson \&
Wisniewski, 1994; Sitton \& Patterson, 1992). Os métodos físico e biológico se constituem em alternativas viáveis e desejáveis em relação ao químico tradicional, principalmente em função de não deixarem resíduos tóxicos nos frutos tratados. Ainda, o emprego dos chamados fungicidas naturais aparece como mais uma opção ao uso dos fungicidas sintéticos, em termos de eficiência de controle (Wilson \& Wisniewski, 1994). 
Atualmente uma das alternativas pesquisadas envolve o uso de extratos vegetais, buscando explorar suas propriedades fungitóxicas. A literatura tem registrado a eficiência de extratos, obtidos de uma gama enorme de espécies botânicas, em promover a inibição do desenvolvimento de vários fitopatógenos de natureza fúngica (Wilson et al., 1997; Kurita et al., 1981).

Dentre os extratos mais pesquisados encontra-se aquele obtido de alho (Allium sativum L.). O seu efeito inibitório tem sido demonstrado para uma extensa gama de fungos, envolvendo não só patógenos de pós-colheita, mas também patógenos foliares e de solo (Tansey \& Appleton, 1975; Chalfoun \& Carvalho, 1987; Bolkhan \& Ribeiro, 1981; Bastos, 1992; Barros et al., 1995). Além do alho, extratos originários de hortelã (Mentha piperita) e pimenta (Capsicum spp) também têm evidenciado propriedades antifúngicas, demonstrando potencial de controle para patógenos de plantas (Wilson et al., 1997; Bastos, 1997). Extratos obtidos de plantas de mamona (Ricinus communis) têm sido relatados como inibidores de fungos associados a substratos de formigueiros, onde a eliminação destes fungos está relacionada ao controle de formigas (Bueno et al., 1990).

Dentre as doenças de pós-colheita, aquelas que ocorrem no mamão são responsáveis por perdas significativas durante 0 armazenamento, transporte e comercialização. Prejuízos de 10 a $40 \%$ em embarques terrestres e de 5 a $30 \%$ em embarques aéreos são comuns, porém, tais perdas podem variar de 1 a $93 \%$ dependendo do manejo de pós-colheita e dos processos de acondicionamento dos frutos (Kretzschmar, 1988). No caso do mamão, a antracnose, causada por Colletotrichum gloeosporioides é apontada como a principal doença de pós-colheita, reduzindo o valor comercial dos frutos (Rezende \& Fancelli, 1997). Segundo estes autores, o fungo provoca uma lesão circular, deprimida, com margem marromclara, produzindo, na porção central, massas de esporos de cor laranja ou rosada. O tecido interno da área infectada é firme, com uma descoloração branca-acinzentada que se torna marrom. Com o progresso da doença, as lesões podem coalescer e causar o apodrecimento do fruto todo.

Tendo em vista a propriedade inibitória de extratos vegetais sobre o desenvolvimento de fungos patogênicos e a importância do fungo $C$. gloeosporioides como agente de podridão em mamão, o presente trabalho teve por objetivo avaliar "in vitro" o efeito de diversos extratos de plantas sobre o crescimento micelial e a produção de esporos de C. gloeosporioides, como uma possível alternativa para o controle da podridão de pós-colheita.

\section{MATERIAL E MÉTODOS}

\section{Isolamento do patógeno}

O fungo C. gloeosporioides foi isolado consistentemente a partir de frutos de mamão apresentando sintomas típicos de podridão. Discos de tecido de $0,5 \mathrm{~mm}$ de diâmetro foram retirados de lesões, na região limítrofe entre a área lesionada e a área sadia. Esses fragmentos foram superficialmente desinfestados com o uso de álcool 70\% (1 minuto) e hipoclorito de sódio 1,5\% (1 minuto). Em seguida, foram transferidos para ágar-água, contido em placas de Petri. Após um período de incubação de 48 horas, a $21^{\circ} \mathrm{C}$ e sob luz NUV constante, discos de $0,5 \mathrm{~mm}$ de diâmetro, retirados dos bordos das colônias, foram transferidos para um meio de BDA contido em tubos. A manutenção dos isolados foi realizada pelo armazenamento dos tubos a $5^{\circ} \mathrm{C}$.

\section{Obtenção de extratos vegetais}

Para a obtenção dos extratos vegetais, foram utilizadas folhas de hortelã e mamona, bulbilhos de alho e frutos de pimenta.

Para extração, foram pesados $5 \mathrm{~g}$ de material vegetal, o qual foi triturado em $50 \mathrm{ml}$ de água destilada esterilizada, durante 10 minutos, em um processador. A seguir o material foi filtrado em papel de filtro (Whatman $n^{\circ} 1$ ) e , posteriormente, em membrana filtrante de porosidade de $0,45 \mathrm{~mm}$. Os extratos aquosos foram utilizados imediatamente após sua obtenção. Para o caso do alho foi utilizado, num ensaio preliminar, extrato esterilizado por filtração e por autoclavagem, isoladamente, para se avaliar a sensibilidade do mesmo ao calor.

\section{Instalação do ensaio}

Os diferentes extratos, individualmente, foram adicionados ao meio de BDA fundente (aproximadamente $45^{\circ} \mathrm{C}$ ), de modo a se obter 
concentrações de 100, 200, 500, 1000, 2000, 5000 e 10000 ppm, onde cada concentração representou um tratamento. Placas contendo somente BDA serviram como testemunhas.

A partir de colônias com 7 dias de idade, crescidas em placas com BDA, sob luz NUV contínua e a $21^{\circ} \mathrm{C}$, foram obtidos discos de $0,5 \mathrm{~mm}$ de diâmetro. Estes discos, individualmente, foram transferidos para o centro de cada uma das placas componentes de cada tratamento. A incubação foi realizada sob luz NUV contínua, a uma temperatura de $21^{\circ} \mathrm{C}$, por um período de 10 dias. Para cada tratamento, foram utilizadas quatro placas, com delineamento experimental do tipo blocos ao acaso, sendo o ensaio repetido duas vezes.

\section{Avaliação}

A avaliação do efeito dos extratos sobre o crescimento micelial foi feita através de medições do crescimento radial da colônia em dois eixos ortogonais, sendo posteriormente calculada uma média. A avaliação foi realizada no $3^{\circ}, 5^{\circ}, 7^{\circ}$ e $10^{\circ}$ dias após a repicagem.

A produção de esporos, foi avaliada no décimo dia, sendo os esporos de cada placa suspensos em $50 \mathrm{~mL}$ de água, acrescidos de uma gota de Tween 20. Para cada placa, três alíquotas de 0,1 $\mathrm{mL}$ foram transferidas, separadamente, para uma lâmina de hemocitômetro, onde se procedeu à contagem de esporos. Os dados médios das três contagens foram transformados em conídios por $\mathrm{cm}^{2}$ de colônia, considerando-se a quantidade de conídios produzidos na área tomada pela colônia em cada placa.

\section{RESULTADOS E DISCUSSÃO}

Todos os extratos testados demonstraram propriedades fungitóxicas a partir da concentração de 200 ppm. O extrato de alho inibiu significativamente o crescimento de micélio (TABELA 1), porém não reduziu a produção de esporos de C. gloeosporioides, mesmo nas concentrações mais elevadas. Por outro lado, os extratos obtidos de hortelã, mamona e pimenta promoveram redução do desenvolvimento de micélio (TABELA 1) e da esporulação do patógeno.

Para todos os extratos utilizados, a redução no desenvolvimento micelial foi crescente proporcionalmente ao aumento das concentrações dos extratos. Os efeitos mais drásticos foram observados para o extrato de alho, sendo o crescimento radial da colônia reduzido em até $67,6 \%$, em relação à testemunha. Para os demais extratos, o efeito fungitóxico compreendeu valores menores quando comparados com aqueles obtidos para o alho. Para pimenta, os valores variaram de 11,03 a $25,75 \%$, respectivamente, para as concentrações de 200 e 10000 ppm, enquanto para mamona e hortelã os limites ficaram entre 8,24 e $31,27 \%$.

O efeito tóxico do alho sobre 0 crescimento de fungos fitopatogênicos também tem sido demonstrado em outros trabalhos. Resultados obtidos por Chalfoun \& Carvalho (1987) revelaram que o extrato de bulbilhos foi altamente eficiente na inibição do crescimento micelial de Gibberella zeae, Alternaria zinniae e Macrophomina phaseolina. Bolkhan \& Ribeiro (1981) constataram que o uso de extrato de bulbilhos na concentração 5000 ppm promoveu

TABELA 1 - Efeito de diversos extratos vegetais incorporados em diversas concentrações em BDA, sobre o crescimento micelial de Colletotrichum gloeosporioides medido através do diâmetro de colônias $(\mathrm{cm})$ com 7dias de idade.

\begin{tabular}{lcccrrrrc}
\hline & \multicolumn{7}{c}{ Concentração $(\mathrm{ppm})$} \\
& 100 & 200 & 500 & 1000 & 2000 & 5000 & 10000 & Testemunha \\
\hline Alho & $7,2 \mathrm{a}$ & $7 \mathrm{~b}$ & $6,8 \mathrm{c}$ & $4,9 \mathrm{~d}$ & $4,4 \mathrm{e}$ & $3 \mathrm{f}$ & $2,4 \mathrm{~g}$ & $7,4 \mathrm{a}$ \\
Hortelã & $6,9 \mathrm{a}$ & $6,5 \mathrm{~b}$ & $6,7 \mathrm{~b}$ & $5,8 \mathrm{c}$ & $5,4 \mathrm{~d}$ & $5,1 \mathrm{e}$ & $5,0 \mathrm{e}$ & $7,1 \mathrm{a}$ \\
Mamona & $7,1 \mathrm{a}$ & $6,5 \mathrm{~b}$ & $6,6 \mathrm{~b}$ & $5,9 \mathrm{c}$ & $5,5 \mathrm{~d}$ & $5,1 \mathrm{e}$ & $5 \mathrm{e}$ & $7,2 \mathrm{a}$ \\
Pimenta & $7,4 \mathrm{a}$ & $6,5 \mathrm{~b}$ & $6,6 \mathrm{~b}$ & $6,6 \mathrm{~b}$ & $5,5 \mathrm{~d}$ & $6 \mathrm{c}$ & $5,8 \mathrm{c}$ & $7,3 \mathrm{a}$ \\
\hline
\end{tabular}

Médias seguidas por letras distintas diferem entre si ao nível de significância de 5\% pelo teste de Tukey $(\mathrm{DMS}=0,22)$. Valor do Coeficiente de Variação $=1,69 \%$. 
inibição de 37, 66 e 76 \% no desenvolvimento de micélio de Cylindrocladium clavatum, Fusarium moniliforme var. subglutinans e Rhizoctonia solani, respectivamente. Bastos (1992) relata uma alta inibição sobre o desenvolvimento de micélio de Crinipellis perniciosa e Phytophthora palmivora, tendo sido observada uma relação direta entre a concentração de extrato no meio e taxa de inibição de crescimento da colônia. Também fungos dos gêneros Curvularia e Alternaria apresentaram menor desenvolvimento de colônia, com valores variáveis de 30 a $75 \%$, quando cultivados em meios contendo extrato de alho nas concentrações de 1000 a 10000 ppm, respectivamente (Barros et al., 1995).

A fungitoxicidade de extratos de alho sobre a germinação de esporos de fungos, tem sido assinalada em vários trabalhos. Tem sido relatada a capacidade fungitóxica do extrato, diminuindo a germinação de esporos sexuados e de conídios de uma gama de fungos patogênicos a plantas (Bastos, 1992; Wilson et al., 1997). No presente trabalho, não foi avaliada a germinação, mas sim a esporulação. Neste aspecto, o extrato de alho não mostrou efeito inibitório sobre a produção de conídios de $C$. gloeosporioides. Logicamente, se for considerado que o extrato reduziu o crescimento de colônia, por conseqüência reduziu também o número total de esporos produzido pelo fungo. No entanto, se for analisado o número de esporos formados por área de colônia, a esporulação não foi afetada de maneira significativa por nenhuma das concentrações testadas.

O extrato de alho esterilizado através filtragem em filtro bacteriológico apresentou atividade antifúngica, contrariamente ao extrato autoclavado que perdeu esta característica durante a esterilização. Isto evidencia que o princípio ativo envolvido é termosensível.

Ao contrário do alho, hortelã, mamona e pimenta inibiram a produção de conídios. $O$ grau de inibição foi maior à medida em que as concentrações destes extratos foram crescentes. A partir da concentração de 200 ppm, o hortelã inibiu a produção de conídios em porcentagens de 18,$2 ; 36,9 ; 43,2 ; 53,2 ; 80,1$ e 83,6 , sendo que para mamona, foram obtidos valores de 18,1 ; 34,$5 ; 41,8 ; 49,0 ; 74,5$ e 81,8 , enquanto para pimenta houve 18,$1 ; 36,3 ; 45,4 ; 54,5 ; 78,7$ e 84,8 de inibição em relação à testemunha. Considerando os três extratos, para as concentrações de 2000, 5000 e 10000 ppm foram constatados valores médios de inibição superiores a $50 \%$. Individualmente, os extratos de hortelã, mamona e pimenta se mostraram altamente eficientes em reduzir a esporulação de C. gloeosporioides, porém não houve destaque de um sobre o outro quanto à eficiência, como pode ser observado pelos resultados obtidos. Se comportaram, portanto, de maneira similar, quanto à sua capacidade em inibir a produção de esporos pelo fungo. É reconhecido que hortelã e plantas do gênero Capsicum, o mesmo da pimenta, apresentam propriedades antimicrobianas (Carpenter, 1945; Wilson et al., 1997). No trabalho conduzido por Wilson et al. (1997) com o fungo Botrytis cinerea foi demonstrado que os extratos obtidos de plantas do gênero Capsicum foram aqueles que apresentaram os maiores índices de atividade antifúngica. Neste mesmo trabalho, hortelã também foi apontado como tendo efeito inibitório moderado sobre a germinação de esporos deste mesmo fungo.

É notório que o volume de trabalhos com alho supera em muito aqueles conduzidos com os outros extratos vegetais e os resultados obtidos neste ensaio não só confirmam as propriedades antifúngicas do alho como também demonstram a atividade de extratos de outras espécies vegetais. É o caso da mamona, por exemplo, para a qual não foi encontrada referência bibliográfica sobre sua atividade contra fungos fitopatogênicos. Além de ter sido altamente eficiente em reduzir a produção de esporos do fungo $C$. gloeosporioides, a mamona apresenta a vantagem de não apresentar o forte odor presente em alho e pimenta, o qual pode impregnar o fruto, se ao extrato for aplicado para tratamento do mesmo. O hortelã, pelas mesmas razões apresentadas para a mamona, também pode ser apontado como potencialmente útil como alternativa de controle da doença, mesmo que de forma parcial.

\section{CONCLUSÕES}

- Os extratos aquosos de alho, mamona, hortelã e pimenta, dentro dos limites de 200 a 10000 ppm, promoveram a inibição relativa do desenvolvimento de micélio do fungo; esta inibição foi diretamente proporcional às concentrações utilizadas.

- Os extratos aquosos de hortelã, mamona e pimenta, nas concentrações de 200 a 10000 ppm, mostraram efeito inibitório sobre a produção de conídios de C. gloeosporioides. 


\section{REFERÊNCIAS BIBLIOGRÁFICAS}

BARROS, S.T.; OLIVEIRA, N.T.; MAIA, L.C. Efeito do extrato de alho (Allium sativum) sobre o crescimento micelial de Curvularia spp e Alternaria spp. Summa Phytopathologica, v.21, p.168-170, 1995.

BASTOS, C.N. Inibição do crescimento micelial e germinação de esporos de Crinipellis perniciosa e Phytophthora palmivora por extrato de bulbo de alho. Fitopatologia Brasileira, v.17, p.454-457, 1992.

BASTOS, C.N. Efeito do óleo de Piper aduncun sobre Crinipellis perniciosa e outros fungos fitopatogênicos. Fitopatologia Brasileira, v.22, p.441-443, 1997.

BOLKHAN, H.A.; RIBEIRO, W.L. Efeito do extrato de alho em Cylindrocladium clavatum, Fusarium moniliforme var. subglutinans e Rhizoctonia solani. Fitopatolologia Brasileira, v.6, p.565-566, 1981.

BUENO, O.C.; HEBLING-BERALDO, M.J.A.; AULINO DA SILVA, O.; PAGNOCCA, F.C.; FERNANDEZ, J.B.; VIEIRA, P.C. Toxic effect of plants on leaf-cutting ants and their symbiotic fungus. In: VAN DER MEER, R.K.; JAFFE, K.; CEDENO, A. (Ed.) Applied myrmecology: a world perspective. San Francisco: Westview Press, 1990. cap.17, p.420-423.

CARPENTER, C.W. Antibacterial properties of yeasts, Fusarium sp, onion and garlic. The Hawaiian Planters Report, v.49, p.41-67, 1945.

CHALFOUN, S.M.; CARVALHO, V.D. Efeito do extrato de óleo industrial de alho sobre o desenvolvimento de fungos. Fitopatolologia Brasileira, v.12, p.234-235, 1987.

ECKERT, J.W.; OGAWA, J.M. The chemical control of postharvest diseases: subtropical and tropical fruits. Annual Review of Phytopathology, v.23, p.421-454, 1985.
KRETZSCHMAR, A. A. Controle biológico de patógenos que ocorrem em pós-colheita. In: BETTIOL, W. (Ed.) Controle biológico de doenças de plantas. Jaguariúna: EMBRAPA, CNPDA, 1988. cap 5, p.53-70.

KURITA, N.; MAKOTO, M.; KURANE, R.; TAKAHARA, Y. Antifungal activity of components of essential oils. Agricultural and Biological Chemistry, v.45, p.945-952, 1981.

REZENDE, J.A.M.; FANCELLI, M.I. Doenças do mamoeiro. In: KIMATI, H.; AMORIM, A.; BERGAMIN FILHO, A.B.; CAMARGO, L.E.A.; REZENDE, J.A.M. (Ed.) Manual de fitopatologia: doenças de plantas cultivadas. São Paulo: Agronômica Ceres, 1997. v.2, cap.46, p.261-297.

SITTON, J.W.; PATTERSON, M.E. Effect of highcarbon dioxide and low oxigen controlled atmospheres on postharvest decays of apples. Plant Disease, v.76, p.992-995, 1992.

TANSEY, M.R.; APPLETON, J.A. Inhibition of fungal growth by garlic extract Mycologia, v.67, p.409-413, 1975.

WILSON, C.L.; WISNIEWSKI, M.E. Biological control of postharvest plant diseases of fruits and vegetables: theory and practice. Boca Raton: CRC Press, 1994. 465p.

WILSON, C.L.; SOLAR, J.M.; GHAOUTH, A.E.; WINIEWSKI, M.E. Rapid evaluation of plant extracts and essential oils for antifungal activity against Botrytis cinerea. Plant Disease, v.81, p.204-210, 1997.

Recebido para publicação em 04.05.99 Aceito para publicação em 13.09.99 